\title{
EFEITOS DO PACLOBUTRAZOL EM DIFERENTES CONCENTRAÇÕES E PERÍODOS DE IMERSÃO NA CULTURA DO ALHO'
}

\author{
GERALDO MILANEZ DE RESENDE, NIVALDO DUARTE COSTA², NATONIEL FRANKLIN DE MELO³ \\ e ROVILSON JOSÉ DE SOUZA ${ }^{4}$
}

\begin{abstract}
RESUMO - O presente trabalho foi conduzido no período de abril a setembro de 1989 no Campo Experimental do Setor de Olericultura da UFLA, Lavras, MG, com o objetivo de avaliar a influência de concentrações e períodos de imersão em paclobutrazol sobre o controle do pseudoperfilhamento e características comerciais do alho (Allium sativum L.). Utilizou-se o delineamento experimental de blocos ao acaso em esquema fatorial $4 \times 5$, compreendendo quatro doses de paclobutrazol $(0,500,1.000$ e $1.500 \mathrm{mg} \mathrm{L}^{-1}$ de i.a.) e cinco períodos de imersão (30, 60, 90, 120 e 150 minutos) e quatro repetições. Observou-se, com o incremento das concentrações de paclobutrazol, uma redução na altura e no número de folhas por planta aos 60 e 90 dias após o plantio. A concentração de $976 \mathrm{mg} \mathrm{L}^{-1}$ de paclobutrazol proporcionou o maior peso médio de bulbo, e a dose de $451 \mathrm{mg} \mathrm{L}^{-1}$ foi a que promoveu a maior porcentagem de bulbos graúdos. Quanto a produtividade total e comercial, porcentagem de bulbos pseudoperfilhados e número de bulbilhos por bulbo, não se verificaram diferenças significativas entre os tratamentos.
\end{abstract}

Termos para indexação: Allium sativum, regulador de crescimento, pseudoperfilhamento, classificação de bulbos.

\section{EFFECTS OF PACLOBUTRAZOL CONCENTRATIONS AND PERIODS OF IMMERSION ON GARLIC CROP}

\begin{abstract}
This study was carried out from April to September of 1989, in the experimental field of UFLA, Lavras, MG, Brazil, with the objective of evaluating the influence of concentrations and periods of immersion of paclobutrazol on secondary growth control and marketable traits in garlic (Allium sativum L.). The experimental design was a randomized complete block in a $4 \mathrm{x} 5$ factorial scheme, with four replications. The first factor consisted of paclobutrazol concentrations $(0,500$, 1,000 and $1,500 \mathrm{mg} \mathrm{L}^{-1}$ of a.i.), and the second one of periods of immersion (30,60, 90, 120 and 150 minutes). Reduction in plant height and in number of leaves per plant from 60 to 90 days after planting with paclobutrazol applications was observed. Mean bulb weight increased up to the concentration of $976 \mathrm{mg} \mathrm{L}^{-1}$ of paclobutrazol, and $451 \mathrm{mg} \mathrm{L}^{-1}$ gave the greatest percentage of bulbs of large size. There was no significant difference among treatments for total and commercial yields, percentage of secondary growth bulbs and number of cloves per bulb.
\end{abstract}

Index terms: Allium sativum, growth regulator, secondary growth, bulb classification.

\section{INTRODUÇÃO}

Os reguladores de crescimento têm apresentado grande potencial de utilização na agricultura em fun-

\footnotetext{
${ }^{1}$ Aceito para publicação em 6 de agosto de 1998 .

${ }^{2}$ Eng. Agr., M.Sc., Embrapa-Centro de Pesquisa Agropecuária do Trópico Semi-Árido (CPATSA), Caixa Postal 23 CEP 56300-000 Petrolina, PE. E-mail gmilanez@cpatsa.embrapa.br

${ }^{3}$ Biólogo, M.SC., Embrapa-CPATSA.

${ }^{4}$ Eng. Agr., Dr., Universidade Federal de Lavras (UFLA), Caixa Postal 37, CEP 37200-000 Lavras, MG.
}

ção de seus efeitos sobre diferentes processos fisiológicos das plantas. Pelo fato de a atuação dessas substâncias de crescimento das plantas poder ser revertida pela aplicação de uma giberelina exógena, estas têm sido identificadas como substâncias antigiberelínicas. O paclobutrazol é um derivado do triazol, com atividade sobre o retardamento de crescimento de plantas (Graebe, 1987), cujo modo de ação consiste na inibição da biossíntese da giberelina (Steffens et al., 1985).

Dentre as anormalidades fisiológicas que ocorrem no alho, o pseudoperfilhamento é considerado 
uma característica comercialmente indesejável, por depreciar o produto e reduzir a produtividade (Burba, 1983). A alta atividade das giberelinas, que induz o pseudoperfilhamento em alho (Moon \& Lee, 1980), sugere que substâncias antigiberelínicas como o paclobutrazol poderiam apresentar algum controle sobre esta anormalidade, possibilitando o uso racional de fatores de produção como o $\mathrm{N}$ e a água.

$\mathrm{Na}$ cultura do alho, a utilização de retardantes de crescimento vem sendo estudada objetivando o controle do pseudoperfilhamento. Foda et al. (1979) verificaram que a imersão de bulbilhos em solução de cycocel e a pulverização de plantas por duas vezes com 1.000 ppm resultaram em maior produtividade, bulbos de maior tamanho, e maior número de bulbilhos por bulbo. Silva (1984), avaliando a influência de chlormequat (1.000ppm) e ácido giberélico (200 ppm), não constatou nenhum efeito desses tratamentos no controle do pseudoperfilhamento.

Com a aplicação de paclobutrazol, Souza (1990) observou redução na altura da planta na cultivar Juréia e menor número de folhas na cultivar B.G.A. 8701, aumentando comercialmente a produção de bulbos das duas cultivares e reduzindo a da cultivar Amarante. No que se refere a peso médio de bulbos, com o incremento das doses, ocorreu uma redução no peso na cultivar Juréia, não se verificando efeito significativo quanto ao número de bulbilhos por bulbo. A incidência de bulbos pseudoperfilhados foi significativamente reduzida nas cultivares Juréia e B.G.A. 8701 .

Resende (1992) verificou, com o incremento das doses de paclobutrazol, um efeito linear sobre a produção total de bulbos, utilizando a cultivar Quitéria, e não encontrou diferenças significativas na produção comercial e na porcentagem de bulbos pseudoperfilhados. Constatou, ainda, a maior produção de bulbos graúdos e médios com a dose de 1.082 e 708 ppm, respectivamente, com um incremento de 10,4 e 6,4\% em comparação com a testemunha. Quanto à produção de bulbos pequenos, verificou um efeito quadrático com ponto de mínima produção na dose de 883 ppm, que promoveu uma redução de 14,7\%, em comparação com a testemunha.

No que se refere às características morfológicas, Resende et al. (1994) relatam que a aplicação de paclobutrazol reduziu a altura de planta, até os
40 dias após o plantio, e não foi eficiente aos 80 dias, nem mostrou diferenças significativas quanto ao número de folhas e ao número de bulbilhos por bulbo.

Neste trabalho procurou-se estudar o efeito do paclobutrazol em diferentes concentrações e períodos de imersão, no controle do pseudoperfilhamento e na melhoria das características comerciais do alho.

\section{MATERIAL E MÉTODOS}

O experimento foi conduzido no período de abril a setembro de 1989, no Campo Experimental do Setor de Olericultura da Universidade Federal de Lavras (UFLA), Lavras, MG, no delineamento de blocos ao acaso, no esquema fatorial $4 \times 5$, compreendendo quatro concentrações de paclobutrazol $\left(0,500,1.000\right.$ e $1.500 \mathrm{mg} \mathrm{L}^{-1}$ de i.a. $)$ e cinco períodos de imersão $(30,60,90,120$ e 150 minutos) com quatro repetições. A área útil da parcela foi de $1,6 \mathrm{~m}^{2}(0,8 \mathrm{~m} \times 2,0 \mathrm{~m})$, e o espaçamento utilizado foi de $0,2 \mathrm{~m}$ entre linhas e $0,1 \mathrm{~m}$ entre plantas dentro das fileiras.

Utilizou-se a cultivar de alho Juréia, e os bulbilhos para plantio foram os retidos na peneira 3 (malha $8 \times 17 \mathrm{~mm}$ ), os quais foram colocados em imersão de acordo com as concentrações e os períodos, e secados à sombra, por um período de 24 horas. O preparo do solo foi o convencional, e a adubação básica de plantio usada, a recomendada por Filgueira (1982). As adubações de coberturas foram realizadas 30 e 60 dias após o plantio, com $100 \mathrm{~kg} \mathrm{ha}^{-1} \mathrm{de}$ sulfato de amônio em cada aplicação.

O plantio foi realizado em 15/04/89, sendo as irrigações por aspersão feitas duas vezes por semana, quando necessárias, até 20 dias antes da colheita, em 20/09/89; as demais práticas culturais foram as comumente recomendas para a cultura do alho. Após a colheita, realizou-se a cura dos bulbos ao sol, por três dias, e à sombra, em galpão, por 60 dias, e fez-se a limpeza cortando-se a parte aérea a $1 \mathrm{~cm}$ dos bulbos e retirando-se as raízes.

Foram avaliadas as seguintes características: altura da planta e número de folhas, 60 e 90 dias após plantio, produção total e comercial, peso médio de bulbo, porcentagem de bulbos pseudoperfilhados, número de bulbilhos por bulbo e classificação de bulbos comerciais em graúdos, médios e pequenos, de acordo com Resende (1992). Os efeitos dos fatores estudados sobre as características avaliadas foram conhecidos mediante a análise de variância e regressão polinomial, com base no modelo quadrático, a $5 \%$ de probabilidade. Os dados referentes à contagem foram transformados em $\sqrt{\mathrm{x}+0,5}$, e os de porcentagem, em $\operatorname{arco-seno} \sqrt{\mathrm{p} / 100}$. 


\section{RESULTADOS E DISCUSSÃO}

Verificaram-se efeitos significativos no tocante às concentrações de paclobutrazol, sem efeito significativo quanto à interação e a períodos de imersão.

Pode-se constatar, pela Fig. 1, uma redução na altura da planta de alho, 60 dias após o plantio, e derivando-se a equação de regressão, obtém-se a concentração de $1.107 \mathrm{mg} \mathrm{L}^{-1}$, como a que possibilitou a menor altura de planta. No que diz respeito à altura, 90 dias após o plantio, verificou-se um efeito linear negativo com o incremento das concentrações de paclobutrazol (Fig. 1). A redução do porte da planta pelo uso deste regulador foi registrada por Souza \& Casali (1992) e por Resende et al. (1994), assim como com outras substâncias consideradas antigiberelínicas que atuam de forma semelhante. Foda et al. (1979) e Souza \& Casali (1991) verificaram que o chlormequat reduziu a altura das plantas de alho, como também Tewari et al. (1984) usando daminozide nas concentrações de 1.000 e $1.500 \mathrm{mg} \mathrm{L}^{-1}$.

Quanto ao número de folhas por planta (Fig. 2), constataram-se efeitos quadráticos, 60 e 90 dias após o plantio. As concentrações de 1.150 e $1.250 \mathrm{mg} \mathrm{L}^{-1}$ foram as que promoveram as maiores reduções no número de folhas, aos 60 e 90 dias, respectivamente;

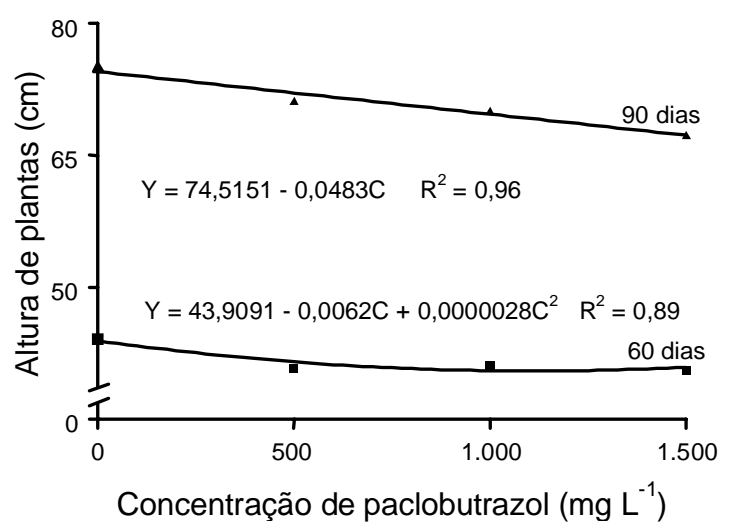

FIG. 1. Altura das plantas de alho entre os 60 e 90 dias após o plantio, em face da concentração (C) de paclobutrazol. contudo, embora significativo, o efeito do produto foi muito pequeno $(3,6$ e $2,7 \%$, respectivamente para 60 e 90 dias após plantio). Souza (1990) encontrou resultados similares usando a cultivar B.G.A. 8701, salientando, também, que o efeito do produto foi muito pequeno, e não observou efeitos sobre a cultivar Juréia. Resende et al. (1994) não observaram efeitos de doses de paclobutrazol sobre o número de folhas da cultivar Quitéria. Sendo as folhas os órgãos vegetativos responsáveis pela atividade fotossintética, o seu maior número determina melhor produtividade. Neste sentido, o pequeno efeito do produto não diminuiu a produtividade neste trabalho; contudo, a redução da altura da planta poderá permitir um melhor arranjo populacional que promoverá incremento na produtividade do alho.

No que se refere à produtividade total e comercial e à porcentagem de bulbos pseudoperfilhados, não se constataram diferenças significativas. Também Silva (1984), usando o cycocel, não observou nenhuma resposta na redução do pseudoperfilhamento, em diferentes épocas de plantio de alho. Ao contrário, Souza \& Casali (1992) encontraram aumentos na produtividade comercial de bulbos e redução na percentagem de bulbos pseudoperfilhados com a aplicação de paclobutrazol, na cultivar Juréia, assim como Resende (1992), na produtividade total, usando a cultivar Quitéria. Salienta-se, entretanto, que

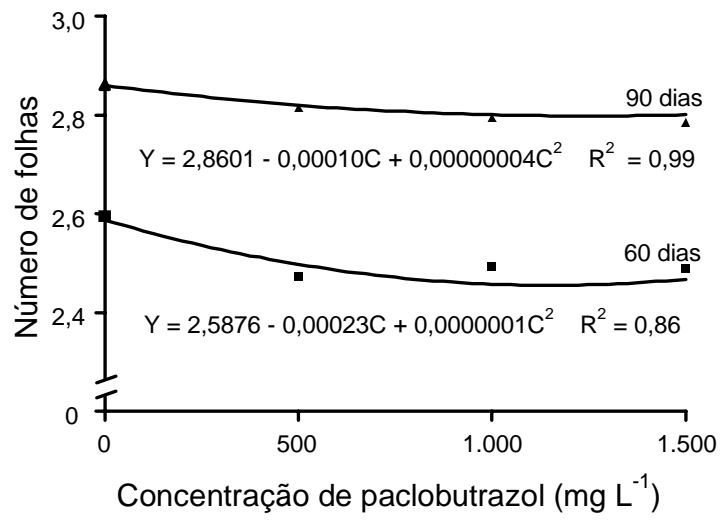

FIG. 2. Número de folhas de alho entre os $60 \mathrm{e}$ 90 dias após o plantio, em face da concentração (C) de paclobutrazol (dados transformados em $\sqrt{x+0,5})$.

Pesq. agropec. bras., Brasília, v.34, n.4, p.635-639, abr. 1999 
mesmo não encontrando diferenças significativas nestas características, no presente trabalho, a concentração de $1.000 \mathrm{mg} \mathrm{L}^{-1}$ de paclobutrazol propiciou produtividade comercial superior em $6,2 \% \mathrm{em}$ relação à testemunha $\left(8,74 \mathrm{t} \mathrm{ha}^{-1}\right)$, assim como a porcentagem de bulbos pseudoperfilhados reduziu a produção em $17,4 \%$, com a concentração de $1.500 \mathrm{mg} \mathrm{L}^{-1}$. Resultados similares foram obtidos quanto ao número de bulbilhos por bulbo, que não diferiram entre si, variando de 23,34 a 24,25 bulbilhos/bulbo. Estes resultados, concordam com os encontrados por Souza (1990) e Resende et al. (1994).

Quanto ao peso médio de bulbos, foi influenciado pelas concentrações de paclobutrazol (Fig. 3), na qual a concentração de $976 \mathrm{mg} \mathrm{L}^{-1}$ sobressaiu-se, superando em $6,8 \%$ a testemunha. Esses resultados contradizem as afirmações de Souza (1990), que verificou redução no peso médio de bulbos com o uso de paclobutrazol, embora a $10 \%$ de probabilidade. Todavia, Resende (1992) não detectou qualquer efeito do produto que alterasse o peso médio do bulbo.

Pela Fig. 4, pode-se observar um aumento na percentagem de bulbos graúdos com as concentrações de paclobutrazol, ocorrendo um efeito quadrático, onde a concentração de $451 \mathrm{mg} \mathrm{L}^{-1}$ promoveu um aumento superior a 4,5\% em relação à testemunha. Quanto à produção de bulbos médios, nota-se um efeito quadrático com ponto de mínima produção na concentração de $385 \mathrm{mg} \mathrm{L}^{-1}$, superando a testemunha em 5,6\%. Resultados similares foram apresentados na produção de bulbos pequenos, nos quais a concentração de $522 \mathrm{mg} \mathrm{L}^{-1}$ se destacou como a que possibilitou a menor produção de bulbos pequenos, ou seja, $16,6 \%$ menor que a da testemunha. Estes resultados são comparáveis aos obtidos por Resende (1992), que evidenciou aumentos na produção de bulbos graúdos e redução na proporção de bulbos de menor tamanho, assim como por Foda et al. (1979), que usando outra substância antigiberelínica, o chlormequat, registraram um aumento significativo no diâmetro do bulbo, em comparação com a testemunha sem aplicação. A possibilidade de se aumentar a porcentagem de bulbos graúdos e reduzir a dos médios e, sobretudo, dos pequenos, é de grande importância para a comercialização do alho, uma vez que os bulbos maiores recebem as melhores cotações nos mercados consumidores.

Pesq. agropec. bras., Brasília, v.34, n.4, p.635-639, abr. 1999

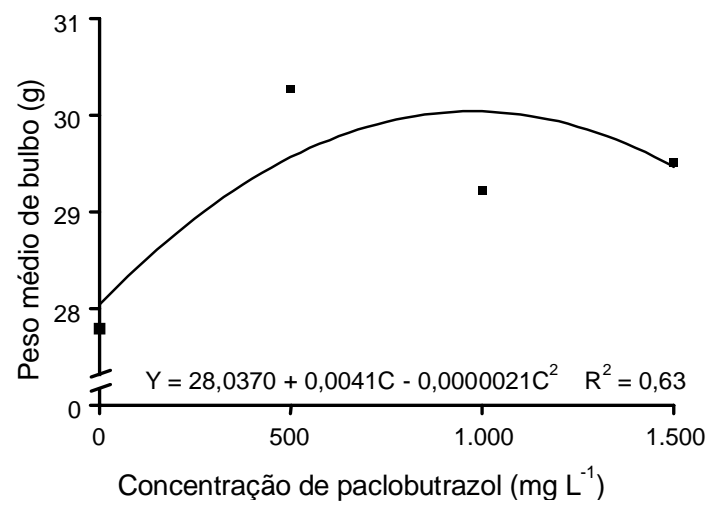

FIG. 3. Peso médio de bulbos de alho em face da concentração (C) de paclobutrazol.

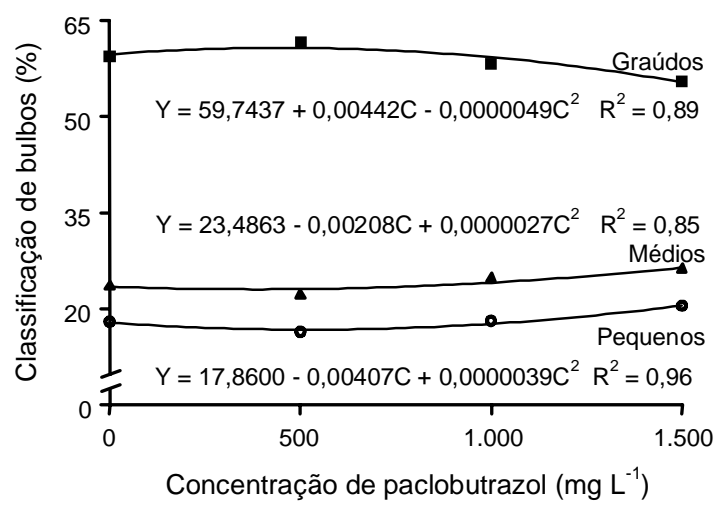

FIG.4. Classificação percentual de bulbos graúdos, médios e pequenos de alho, em face da concentração (C) de paclobutrazol (dados transformados em arco-seno $\sqrt{\mathrm{x} / 100})$.

\section{CONCLUSÕES}

1. O paclobutrazol reduz a altura e o número de folhas de alho entre os 60 e 90 dias após o plantio.

2. A produtividade total e comercial de bulbos de alho, a porcentagem de bulbos pseudoperfilhados e o número de bulbilhos por bulbo não são afetados pelo uso de paclobutrazol.

3. O paclobutrazol proporciona grande incremento na produção de bulbos graúdos de alho, e reduz a porcentagem de bulbos de menor tamanho. 


\section{REFERÊNCIAS}

BURBA, J.L. Efeitos do manejo de alho-semente (Allium sativum L.) sobre a dormência, crescimento e produção da cultivar Chonan. Viçosa: UFV, 1983. 112p. Tese de Mestrado.

FILGUEIRA, F.A.R. Manual de olericultura: cultura e comercialização de hortaliças. São Paulo: Agronômica Ceres, 1982. 357p.

FODA, S.A.; SALEH, H.H.; SHAHEIN, A.H. Effect of cycocel "Chlormequat" on garlic. Agricultural Research Review, v.57, n.3, p.171-177, 1979.

GRAEBE, J.E. Gibberelin biosynthesis and control Annual Review Plant Physiology, v.38, p.419-465, 1987.

MOON, W.; LEE, B.Y. Influence of short day treatment on the growth and levels of endogeneus growth substances in garlic plants (Allium sativum L.). Journal Korean of the Society for Horticultural Science, v.21, n.2, p.109-118, 1980.

RESENDE, G.M. de. Influência do nitrogênio e paclobutrazol na cultura do alho (Allium sativum L.) cv. “Quitéria”. Lavras: ESAL, 1992. 107p. Tese de Mestrado.

RESENDE, G.M. de; SOUZA, R.J. de; LUNKES, J.A. Efeito do nitrogênio e paclobutrazol sobre algumas características morfológicas e perda de peso de plantas e bulbos de alho (Allium sativum L.) cv. Quitéria.
Ciência e Prática, Lavras, v.18, n.3, p.274-279, jul./set. 1994.

SILVA, N.F.D. da. Estudo da superação da dormência, crescimento e produção do alho (Allium sativum L.) cv. Peruano submetido a frigorificação, calor e lavagem pré-plantio e efeito de fitorreguladores na produção e nos aspectos comerciais. Viçosa: UFV, 1984. 86p. Tese de Mestrado.

SOUZA, R.J. de. Influência do nitrogênio, potássio, cycocel e paclobutrazol na cultura do alho (Allium sativum L.). Viçosa: UFV, 1990. 143p. Tese de Doutorado.

SOUZA, R.J. de; CASALI, V.W.D. Influência do nitrogênio e cycocel na cultura do alho (Allium sativum L.). Ciência e Prática, Lavras, v.15, n.1, p.69-78, jan./mar. 1991.

SOUZA, R.J. de; CASALI, V.W.D. Influência do paclobutrazol na cultura do alho (Allium sativum L.). Ciência e Prática, Lavras, v.16, n.2, p.246-251, abr./jun. 1992.

STEFFENS, G.L.; BYUN, J.K.; WANG, S.Y. Controlling plant growth via the gibberellin biosynthesis system. I. Growth parameter alterations in apple seedlings. Physiologia Plantarum, v.63, n.2, p.163-168, 1985.

TEWARI, J.P.; AWASTHI, D.N.; KANAUJIA, J.P.; JOSHI, K.R. Effect of growth retardants on the growth and yield of single clove garlic. Progressive Horticulture, v.16, n.3/4, p.199-201, 1984. 